action learning sets, 360 degree feedback on their leadership behaviours and the opportunity to lead on a specific service or practice development project relevant to their role.

Results Evaluation demonstrated that participants developed their abilities in:

- self-awareness, self-management and personal development;

- developing and enhancing person-centred services and care;

- managing effective relationships with team members within the hospice;

- networking and partnership working.

In addition participants designed and led a quality improvement project specific to their own area of work which supported the implementation of the hospice strategy.

\section{P-75 IMPROVED MANAGEMENT PRACTICE THROUGH A FOCUSED DEVELOPMENT PROGRAMME}

Elizabeth Pattison. Peace Hospice Care, Watford, UK

\subsection{6/bmjspcare-2019-HUKNC.98}

Background In 2016 we introduced a Management Development Programme for senior managers. Programme evaluation highlighted benefits: managers bonded, gained a sense of collective responsibility, felt more confident in their roles and improved their communication within teams. Consequently, the programme was repeated for next level of management.

Aims To evaluate this second programme using the Kirkpatrick Model (Evaluating training programs, 1994), focusing on impact of managers' behaviours in relation to implementation of policies and performance management.

Method After modules attendees completed an evaluation/feedback questionnaire that measured reaction (level 1 evaluation) and learning (level 2 evaluation). Changes in behaviour (level 3 evaluation) were undertaken through individual interviews and group reflection session.

Results Initial reactions of attendees (Level 1):

- $99.5 \%$ agreed course was relevant to them;

- $96.5 \%$ agreed quality of training was high;

- $95.5 \%$ agreed session(s) would be useful in their work.

Learning (level 2) was evaluated through the question 'How do you hope to change your practice as a result of this training?' This question was answered $57 \%$ of the time and answers included: improvement in communication, confidence, management style. Some $18 \%$ of those who answered said they needed to reflect.

Examples given of subsequent changes in management behaviour (level 3 evaluation) included: increased confidence and assertiveness in performance management and management styles, more proactive sickness absence management, improved job descriptions and interview questions resulting in recruitment of higher calibre employees.

Quantitative longer-term results (level 4 evaluation) have yet to be established. Financial savings have been made through the proper management of long-term sickness absence.

Conclusion Evaluation of results (level 4) of this programme is ongoing through sickness absence, exit questionnaire, staff survey, performance management and appraisal monitoring. We plan to extend the programme in $2020 / 21$.

\section{P-76 DEVELOPING AND IMPLEMENTING A LEADERSHIP PROGRAMME FOR HOSPICE COMMUNITY NURSES}

Toni Flanagan, Helen Reeves, Katie Taroni. St Giles Hospice, Lichfield, UK

10.1136/bmjspcare-2019-HUKNC.99

Background and aims The aim of this project was to introduce an innovative leadership programme aimed at hospice nurses within the community palliative care team to help enhance their leadership skills and build resilience to reduce the risk of burnout. The programme aimed to develop nursing leadership skills, to enhance patient care and to improve practitioner self-management. To ensure the programme reflects the needs of the individuals and the group as a whole, a range of teaching and learning methods were employed. The programme included Myers Briggs Type Indicator (MBTI), FIERCE training, training on self-management techniques and change, group coaching and a workbook which supported the programme with self-reflection exercises. The programme was underpinned by the Clinical Leadership Competency Framework (NHS Leadership Academy, 2011) to ensure optimisation of leadership potential.

Method Focus groups were used to gather information from the participants regarding their understanding of leadership and how they felt about themselves as leaders.

Results Prior to the programme participants felt that the traits of a leader and the relationship between leader and follower were of paramount importance. There was also an acknowledgement from the participants that they did not self-identify as leaders in their role. Following the leadership programme further focus groups were used to evaluate the programme. Participants felt they had increased their confidence around their leadership skills and the programme had helped them to understand themselves and others more which they felt led to better team working which consequently increased resilience. Questionnaires were also used to demonstrate change in individuals with most showing an improvement in their confidence, self-management and team working.

Conclusion Overall, the evaluation of the leadership programme was extremely positive with the only suggested improvement to shorten the one-year programme to intensify the experience.

\section{P-77 RESTORATIVE PRACTICE: EMOTIONAL INTELLIGENCE IN THE WORKPLACE}

Ann Smith, Lesley Spencer. Princess Alice Hospice, Esher, UK

10.1136/bmjspcare-2019-HUKNC.100

Background/context In recent years evidence suggests that a happier workforce improves productivity and the quality of care being delivered to its service users. Restorative practice is an alternative, yet effective response to improving performance and avoiding unnecessary grievances. This approach saves time and the anxiety that can occur when there is conflict and unhappiness in the workplace. Restorative practice helps people to find their own solutions to problems and focuses more on the person rather than procedure.

Aim In 2016, the clinical department at Princess Alice Hospice began to adopt a less procedural approach to managing staff, and saw as a result the number of grievances fall with a happier workforce that played to the strengths of individuals. In 